\title{
Rise in lens temperature on exposure to sunlight or high ambient temperature
}

\author{
ABDULRAHMAN A AL-GHADYAN' AND EDWARD COTLIER \\ From 'King Faisal University College of Medicine and Medical Sciences, Dammam, Saudi Arabia, and the \\ ${ }^{2}$ Department of Ophthalmology and Visual Sciences, Yale University School of Medicine, New Haven, \\ Connecticut, USA
}

SUMmaRY The effect of increase ambient temperature and sunlight on the temperatures of the rabbit lens and posterior chamber (PC) aqueous humour was measured by needle thermistor probes while the rectal temperature was monitored. Exposure of rabbits to sunlight $\left(35^{\circ}-42^{\circ} \mathrm{C}\right)$, in New Haven, Connecticut, USA, resulted in significant temperature increases in $\mathrm{PC}\left(4 \cdot 3^{\circ} \mathrm{C}\right)$, lens $\left(3 \cdot 2^{\circ} \mathrm{C}\right)$, and rectum $\left(2 \cdot 3^{\circ} \mathrm{C}\right)$. Returning animals to the shade resulted in a progressive decrease in the temperatures of the PC or lens in the tested eye, but repeating exposure to sunlight resulted in significant increases of the baseline (PC) temperature (increase $2.68^{\circ} \mathrm{C}$ ) of the second eye. Exposure of rabbits to sunlight at $49^{\circ} \mathrm{C}$ in Chandigarh, India, resulted in increased $\mathrm{PC}$ temperature of $4.48^{\circ} \mathrm{C}$ after 9 minutes. Increased PC and lens temperatures after exposure to sunlight are due both to an ambient temperature effect through the cornea and to increased body temperature. In dry and hot tropical areas of the world temperature increases in the lens after exposure to sunlight may initiate or accelerate the formation of senile cataracts.

The possible association of senile cataracts with incident radiant energy of any wavelength on the lens was first proposed by Duke-Elder in 1926.' Goldmann in 1933 induced posterior subcapsular cataracts in animals by prolonged exposure to heat. ${ }^{2}$ More recently several studies have revealed that lens protein or tryptophan solution exposed to sunlight or ultraviolet light will change its colour and fluorescence in a similar way to that of cataractous lenses. ${ }^{34}$ Furthermore, photoperoxidation of kynurenine, a tryptophan derivative, may act as a photosensitiser, mediating light induced non-disulphide cross-linking of protein as found in human cataracts. ${ }^{5}$ Ultraviolet light has been implicated in the possible sunlight effects, either as initiator or accelerator of cataracts in sunny or tropical areas of the world. ${ }^{678}$ From a recent analysis of the epidemiological data from Hawaii ${ }^{4}$ it appears that other physical factors besides ultraviolet are involved in cataractogenesis. In this regard Minassian et al." found that dehydrational crisis from heat stroke increases the risk of cataracts by a factor of 1.75 and that exposure to both heat stroke and severe diarrhoea increases by 15 -fold the Correspondence to Dr A Al-Ghadyan, PO Box 4190, Dammam, Saudi Arabia. risk of having cataract. It appears that high ambient temperature may play a part in cataract formation.

The lens is seriously influenced by increased ambient temperature. Voaden " found that lysis and cell death occurred in cultured rabbit lens epithelial cells exposed to $38^{\circ} \mathrm{C}$ or higher. Edwards et al..$^{12}$ found cell death in the central nervous system and cataract formation in guinea-pig embryos following maternal exposure for 15 hours to $42-42.5^{\circ} \mathrm{C}$ on the twentyfirst day of gestation.

The presence of a temperature gradient between corneal surface and vitreous cavity, which disappeared if the lids were kept closed, was shown in rabbits by Schwartz, ${ }^{1.3}$ who also noticed that lowering environmental temperature decreased lens temperature. ${ }^{14}$

The thermal energy generated by sunlight might have a major role in cataract formation, as the lens is placed behind the iris pigment epithelium. Increases in temperature in the posterior chamber during experimental xenon arc or laser photocoagulation resulted in cataract formation. ${ }^{16}$ To determine the role of sunlight on the temperatures of the lens and posterior chamber aqueous humour rabbits were exposed to mid-day sunlight. However, concomit- 
ant body temperature increases were found in the animals due to environmental heating. This led to a series of experiments conducted indoors which helped to clarify the role of environmental heating on lens and posterior chamber temperatures.

\section{Material and methods}

Pigmented rabbits weighing about $2.5 \mathrm{~kg}$ were anaesthetised with intravenous pentobarbitone (Nembutal) in doses of $20 \mathrm{mg} / \mathrm{kg}$ body weight. A lid retractor was placed in one eye. The posterior chamber was entered through the sclera approximately $2 \mathrm{~mm}$ from the corneoscleral limbus with a 24 gauge thermistor needle probe (No. 524) with time constant of $0 \cdot 1$ second plugged to a model 46 TUC telethermometer (YSI Co.). ${ }^{17}$ About $7 \mathrm{~mm}$ of the metallic probe was inserted into the eye; the remaining part was covered with a plastic tube to minimise the heat loss or gain causing the error reported by Fatt and Forester. ${ }^{18} \mathrm{~A}$ similar probe was inserted into the anterior lens cortex through the opposite side of the same eye. The body temperature was recorded by a rectal probe (401) with a time constant of 7 seconds. Air temperature was measured with a mercury-inglass thermometer certified to $0 \cdot 1^{\circ} \mathrm{C}$ which had been used to calibrate the probes.

\section{OUTDOOR EXPERIMENTS}

(a) In New Haven, Connecticut. The experiments were conducted on six pigmented rabbits (12 eyes)

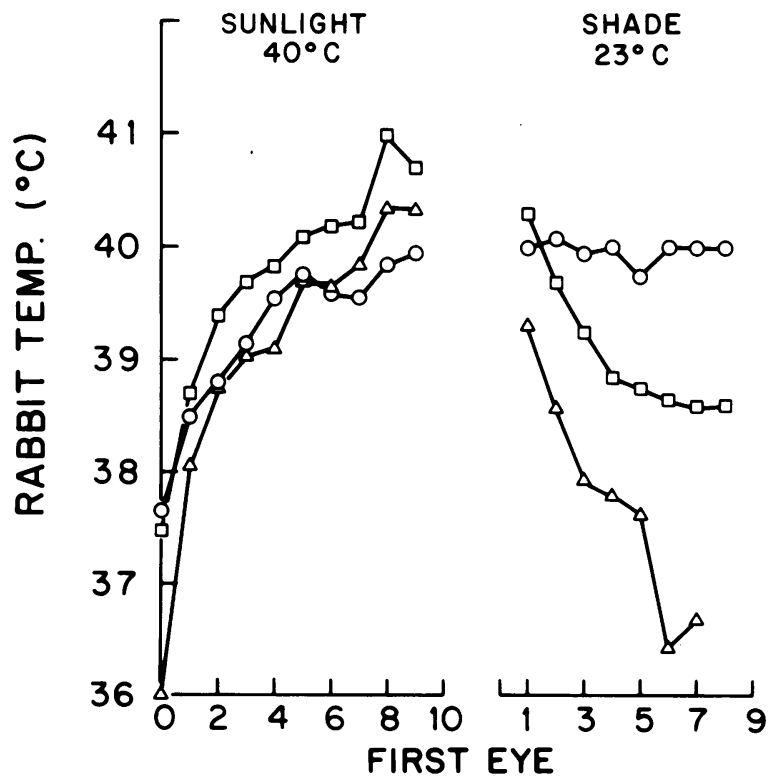

during the month of July on the roof of a 10-story building with walls shielding the area from wind and totally exposed to sunlight between $11.30 \mathrm{am}$ and $12.30 \mathrm{pm}$. Ambient temperatures in the shade varied from 28 to $30^{\circ} \mathrm{C}$ and in the sunlight from 35 to $42^{\circ} \mathrm{C}$ during the course of the experiments. In each experiment temperatures were recorded from eye No. 1 with one probe in the lens, another one in the posterior chamber, and the third in the rectum for at least 9 minutes. Then the animals with the probes in place were moved to the shade, and the recording continued for at least 7 minutes. After the conclusion of the experiments on eye No. 1 we repeated the same procedure on eye No. 2 .

(b) In Chandigarh, India. The experiments were conducted on six pigmented rabbits in a large courtyard between 11.30 am and $12.30 \mathrm{pm}$. Ambient temperatures of $37^{\circ} \mathrm{C}$ in the shade and $49^{\circ} \mathrm{C}$ in the sunlight precluded experiments lasting longer than 20 minutes owing to intense dehydration of the investigators and probably of the experimental animals.

(c) Also in India under similar circumstances another experiment was conducted on the eyes of one monkey. With the same probes the posterior chamber and lens temperatures were recorded. The effect of a $1 \%$ transmission filter was tested.

\section{INCUBATOR EXPERIMENTS}

The rabbit was placed inside an infant incubator (Air Shield Co.) and the temperature probes were placed in the posterior chamber, the lens, and the rectum. A

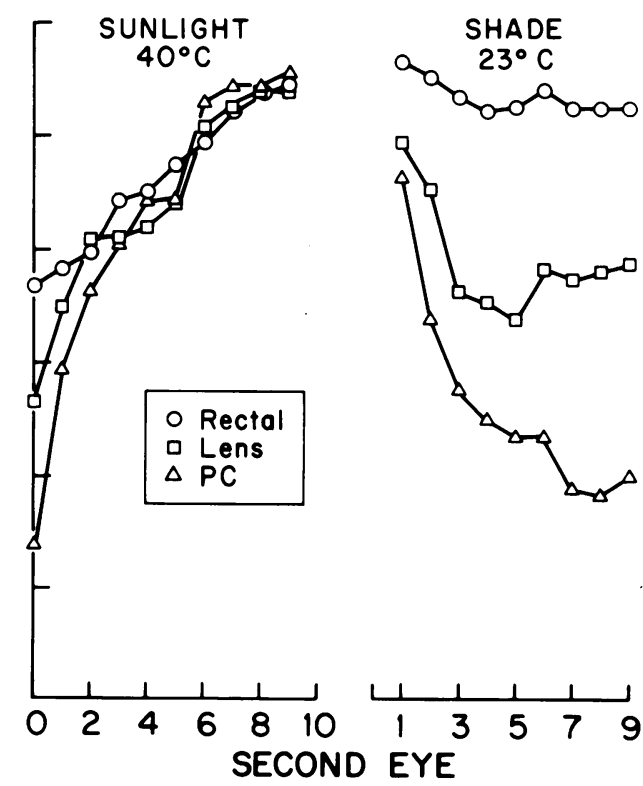

Time (min)

Fig. 1a Representative diagrams of the experiments in pigmented rabbits conducted in (a) New Haven (see Fig. Ib). 
mercury-in-glass thermometer was used to measure incubator temperature. The incubator temperature was raised to $50^{\circ} \mathrm{C}$ by exposure to a heated air blower attached to one of the incubator's portholes. Temperatures were recorded every minute for at least 9 minutes. When heating was discontinued, the incubator doors were opened to allow equilibration with the room temperature. The recording of temperature was continued every minute during the following 7 minutes. The probes were transferred to the second eye and the same procedures were repeated as above. The experiments were done with the animal in the incubator on one occasion and with only the head inside or outside the incubator on other occasions.

\section{Results}

In the outdoor experiments performed in New Haven, where the mean ambient temperature in the shade was $29^{\circ} \mathrm{C}$ and in the sun $38.5^{\circ} \mathrm{C}$, exposure of the animal to sunlight resulted in a progressive increase of the temperatures of the posterior chamber, the lens, and the rectum. The rise in these temperatures recorded from eye No. 1 was as follows: $(a)$ in the posterior chamber $4.3^{\circ} \mathrm{C},(b)$ in the lens $3 \cdot 2^{\circ} \mathrm{C},(c)$ in the rectum $2 \cdot 3^{\circ} \mathrm{C}$ (Fig. 1, Table 1). Exposure of the animals to stronger sunlight in a warm environment such as our experiment in India, where the temperature was $49^{\circ} \mathrm{C}$, resulted in slightly higher temperatures in the posterior chamber $\left(4.48^{\circ} \mathrm{C}\right)$ and the lens $\left(3 \cdot 5^{\circ} \mathrm{C}\right)$ (Fig. 1, Table 1$)$. The temperature recordings from the posterior chamber of the two eyes of a monkey rose from $36^{\circ} \mathrm{C}$ to $41.5^{\circ} \mathrm{C}$ after approximately 9 minutes of exposure, and when a $1 \%$ Kodak filter was introduced the posterior chamber temperatures dropped to $40^{\circ} \mathrm{C}$ (Fig. 2).

When we did the experiment with the whole body inside the incubator, when the incubator temper-

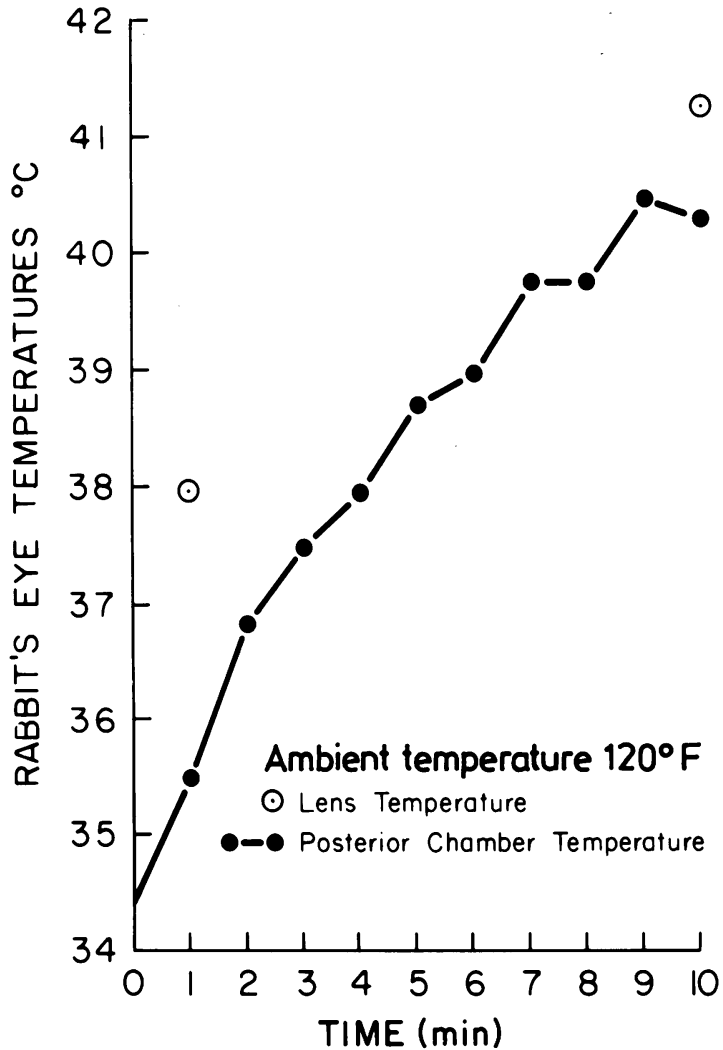

Fig. 1b and India. On the abscissa is shown the exposure time to sunlight or to shade in minutes and on the ordinate the corresponding changes in rectal, lens, and posterior chamber temperatures.

ature was higher than that of the field experiment, we obtained less rise in the temperatures of the posterior chamber, the lens, and the rectum. This points to the significance of direct exposure to sunlight in raising the eye and body temperatures. The rise in these

Table 1 Posterior chamber, lens, and rectal temperatures $( \pm S D)$ recorded from eye No. 1 and eye No. 2 of pigmented rabbits, comparing the effect of direct exposure to sunlight with exposure to a heated environment

\begin{tabular}{|c|c|c|c|c|c|c|}
\hline & \multirow[t]{2}{*}{ No. of animals } & \multirow{2}{*}{$\begin{array}{l}\text { Duration in } \\
\text { minutes }\end{array}$} & \multicolumn{4}{|c|}{ Temperature recorded in ${ }^{\circ} \mathrm{C}$} \\
\hline & & & $\begin{array}{l}\text { Posterior } \\
\text { chamber }\end{array}$ & Lens & Rectal & Ambient \\
\hline $\begin{array}{l}\text { Eye 1 } \\
\text { Baseline temperature } \\
\text { Sunlight experiment }\end{array}$ & 6 & - & $36 \cdot(02 \pm 0 \cdot 59$ & $37 \cdot 50 \pm 0 \cdot 45$ & $37 \cdot 65 \pm 0 \cdot 42$ & $29 \pm 0 \cdot 5$ \\
\hline $\begin{array}{l}\text { New Haven, USA } \\
\text { Chandigarh, India } \\
\text { Indoor experiment }\end{array}$ & $\begin{array}{l}6 \\
6 \\
6\end{array}$ & $\begin{array}{l}9 \\
9 \\
9\end{array}$ & $\begin{array}{l}40 \cdot 32 \pm 0 \cdot 67 \\
40 \cdot 50 \\
38 \pm 0 \cdot 37\end{array}$ & $\begin{array}{l}40 \cdot 7 \pm 0 \cdot 54 \\
41 \cdot 00 \\
38 \cdot 38 \pm 0 \cdot 41\end{array}$ & $\begin{array}{l}39 \cdot 97 \pm 0 \cdot 45 \\
39 \cdot 42 \pm 0 \cdot 25\end{array}$ & $\begin{array}{l}38 \cdot 5 \pm 0 \cdot 4 \\
49 \pm 1 \cdot 1 \\
49 \cdot 17 \pm 0 \cdot 80\end{array}$ \\
\hline $\begin{array}{l}\text { Eye } 2 \\
\text { Bascline temperature } \\
\text { Sunlight experiment }\end{array}$ & 6 & - & $38 \cdot 7 \pm 0 \cdot 47$ & $39 \cdot 7 \pm 0 \cdot 18$ & $41 \pm 0 \cdot 36$ & $45 \cdot 75 \pm 1 \cdot 56$ \\
\hline $\begin{array}{l}\text { New Haven } \\
\text { Indoor experiment }\end{array}$ & $\begin{array}{l}6 \\
6\end{array}$ & $\begin{array}{l}9 \\
9\end{array}$ & $\begin{array}{l}41 \cdot 55 \pm 0 \cdot 54 \\
38 \cdot 85 \pm 0 \cdot 35\end{array}$ & $\begin{array}{l}41 \cdot 47 \pm 0.42 \\
39 \cdot 73 \pm 0.21\end{array}$ & $\begin{array}{l}41 \cdot 45 \pm 0 \cdot 38 \\
40 \cdot 50 \pm 0 \cdot 24\end{array}$ & $\begin{array}{l}50 \pm 0 \cdot 0 \\
38 \cdot 5 \pm 0 \cdot 4\end{array}$ \\
\hline
\end{tabular}


Fig. 2 Representative diagram of the experiments conducted on a monkey in India. On the abscissa is shown the exposure time to sunlight in minutes and on the ordinate the corresponding changes in posterior chamber and lens temperatures. Note the significant reduction of posterior lens temperature after covering the eye with a $1 \%$ to sunlight. transmission filter during exposure

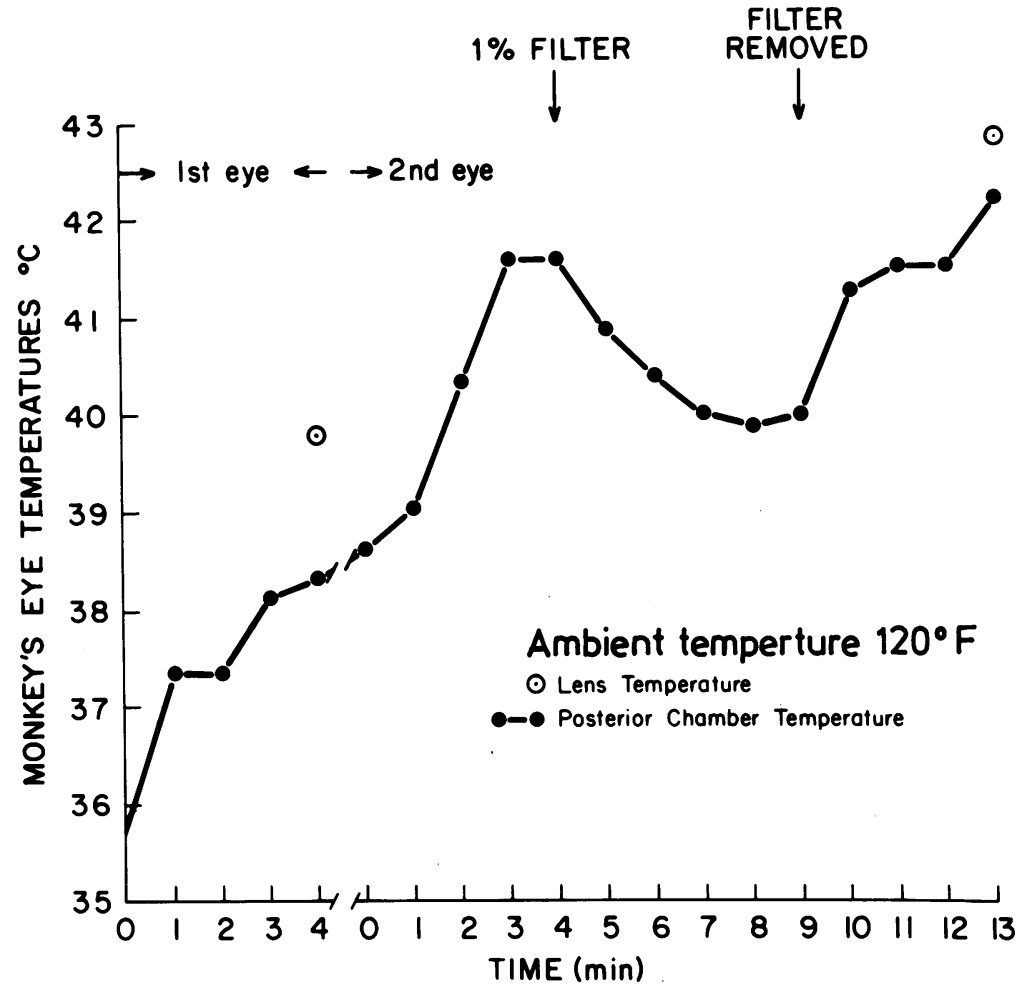

temperatures recorded for eye No. 1 was as follows: $(a)$ in the posterior chamber $2.32^{\circ} \mathrm{C}(b)$ in the lens $2.32^{\circ} \mathrm{C}$, and $(c)$ in the rectum $0.55^{\circ} \mathrm{C}$ (Table 1 ). When the temperature was allowed to drop (in both outdoor and indoor experiments) for 7-8 minutes, the recorded temperatures decreased to a degree higher than the baseline temperature at zero time in eye No. 1 . The outdoor experiments (Table 2 ) tended to give the higher recordings.

The final recordings at the end of 9 minutes from eye No. 2 (Table 1) showed higher temperatures in the posterior chamber, lens, and rectum than were obtained at the end of 9 minutes in eye 1 in both outdoor and indoor experiments. These were attributed to the retained temperature from the experiment done in eye No. 1. Thus prolonged exposure to sunlight or a heated environment will increase eye and body temperatures.

In order to dissociate the effect of body temperature from the environmental temperature an experiment was performed by placing the head of the rabbits either inside or outside the incubator. Comparing the recordings from the head-out experiments in both eye No. 1 (minimal rise) and eye No. 2

Table 2 Posterior chamber, lens, and rectal temperatures ( $\pm S D)$ recorded from eye No. 1 and eye No. 2 of pigmented rabbits at the end of 7-8 minutes after discontinuing sunlight or heat

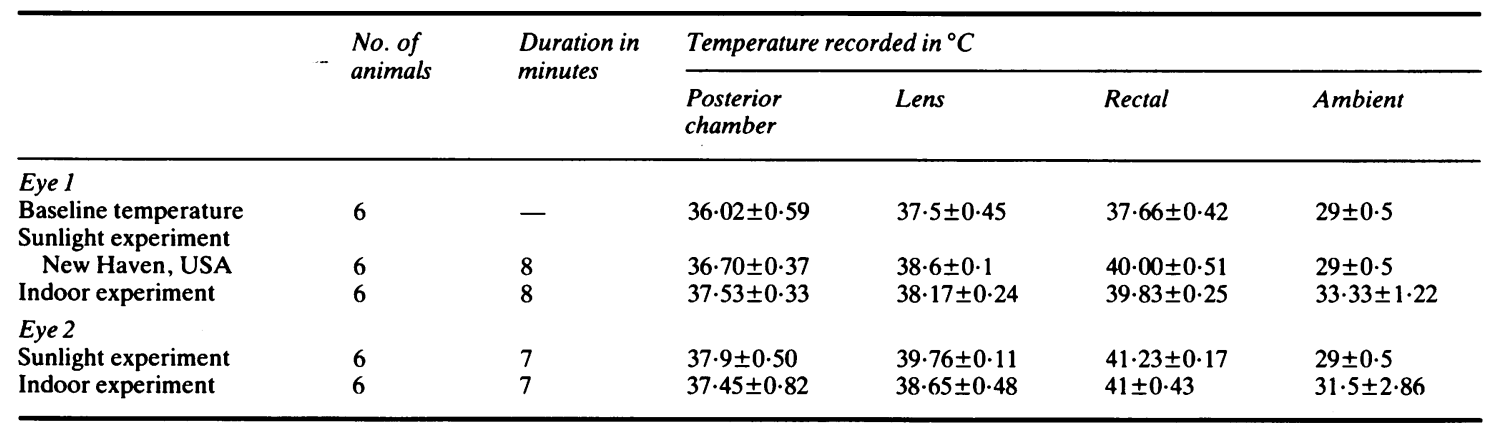


Table 3 Recordings from posterior chamber, lens, and rectum from eye No. 1 and eye No. 2 of pigmented rabbits after 9 minutes exposure either totally or partially to a heated incubator.

Temperature recorded in ${ }^{\circ} \mathrm{C}$

$\begin{array}{llll}\begin{array}{l}\text { Posterior } \\ \text { chamber }\end{array} & \text { Lens } & \text { Rectal } & \text { Incubator }\end{array}$

Posterior
chamber

Eye 1

Baseline temperature

Total body inside

Only head inside

Only head outside

Eye 2

Total body inside

Only head inside

Only head outside

$\begin{array}{ll}36 \cdot 02 & 37 \cdot 5 \\ 38 & 38 \cdot 38 \\ 37 & 37 \cdot 5 \\ 33 & 35 \cdot 5 \\ & \\ 38 \cdot 85 & 39 \cdot 75 \\ 37 \cdot 8 & 38 \cdot 5 \\ 37 \cdot 5 & 38 \cdot 5\end{array}$

$37 \cdot 65$

39.42

$37 \cdot 8$

39

$40 \cdot 50$
39

39

39 (significant rise) with those from total-body and head-in experiments clearly illustrates the role of rise in both body and ambient temperatures on the temperatures of the lens and the posterior chamber (Table 3).

\section{Discussion}

Evidence indicating a possible role of sunlight and ultraviolet light on the formation of senile cataract had been summarised by Zigman. ${ }^{6}$ The visible and infrared components of sunlight can raise posterior chamber and lens temperatures, as shown in experiments on heat absorption by the iris and their effect on the lens. ${ }^{16}$ Our experiments represent the first measurement of lens and posterior chamber temperatures under experimental conditions which may simulate those of human eyes exposed to sunlight.

The rise in posterior chamber and lens temperatures of pigmented rabbits exposed to sunlight was due to a variety of factors, some of which were analysed in the experiments. The outdoor experiments in New Haven revealed that 9 minutes' exposure to sunlight resulted in an increase in lens temperature which was maintained even after exposure to sunlight had been discontinued. Furthermore, it would appear that, in rabbits which were already exposed to sunlight and had an increased body temperature, the temperature in the second eye rose to levels above $41^{\circ} \mathrm{C}$, which could accelerate a variety of metabolic reactions. If heat is accumulated, the higher temperatures could accelerate or initiate chemical cataractogenic processes such as glycosylation or carbamylation of lens proteins.

The rise in lens and posterior chamber temperatures following exposure to sunlight represented the combined effect of thermal absorption by the pigment epithelium of the iris plus the temperature increases which resulted from exposure of the eye and the body to a warmer environment. The in- creased body temperatures which resulted from exposure to sunlight were analysed by the indoor experiments in the incubator. It appeared that a $1.77^{\circ} \mathrm{C}$ increase in body (rectal) temperature is associated with increased posterior chamber and lens temperatures by $1.98^{\circ} \mathrm{C}$ and $0.88^{\circ} \mathrm{C}$ respectively. This rise in lens temperature resulted from both transmitted body heat and environmental heat. However, in rabbits exposed to sunlight (New Haven), higher rises in posterior chamber $\left(4 \cdot 3^{\circ} \mathrm{C}\right)$ and lens $\left(3 \cdot 2^{\circ} \mathrm{C}\right)$ temperatures were found despite an increased in body (rectal) temperature of $2 \cdot 3^{\circ} \mathrm{C}$. Thus, the combined body and environmental factors did not account for the whole rise but for approximately $30 \%$ of the sunlight-induced rise of lens temperature. This was substantiated by the results from exposure to high environmental temperatures with the head inside or outside a heated incubator.

Temperature increase induced modification in the distribution of lens crystallin. $\mathrm{Lu}-\mathrm{Ku}-\mathrm{Li}$ demonstrated that the lens protein subfractions were altered by increasing the temperature during gel filtration chromatography from $8^{\circ} \mathrm{C}$ to $40^{\circ} \mathrm{C} .^{19} \mathrm{He}$ found a gradual disappearance of the $B_{h}$ crystallin and to a less extent of $\gamma$ crystallin with rise in temperature and reappearance of a new high molecular weight $\beta$ crystallin which was not present in the profile obtained at $8^{\circ} \mathrm{C}$. The $\mathrm{SH}$ moiety of cystein was found to be essential for the formation of this high molecular weight protein. Voaden found lysis and death of the rabbit lens epithelial cells in cell culture when exposed to $38^{\circ} \mathrm{C}$ or higher. "In our experiments we found that raising the incubator temperature to $50^{\circ} \mathrm{C}$ for a short period of time produced a $0.88^{\circ} \mathrm{C}$ rise in lens temperature, while exposure to sunlight at $40^{\circ} \mathrm{C}$ led to a $3 \cdot 2^{\circ} \mathrm{C}$ rise in lens temperature. The prolonged temperature rise which occurs in very warm countries may be sufficient to change the metabolism and the transparency of the lens. However, the contribution of long-term high-temperature 
exposure to cataract formation is not known. High lens temperatures do accelerate lens metabolism and may effect lens elasticity. Miranda found that presbyopia is directly correlated with ambient temperature rather than exposure to ultraviolet light. ${ }^{20}$ Moreover in a study conducted in the Punjab the incidence of cataract was found to be greater in the plains than in the mountains, where the ultraviolet light is higher and the temperature is lower. ${ }^{21} \mathrm{We}$ believe that the development of human senile cataract is better correlated with both high ambient temperature and exposure to sunlight (ultraviolet and infrared). The recent studies of Minassian et al." associated the increased ambient temperature in various areas of the Punjab with the risk of cataracts due to diarrhoea, heat stroke, or both. Increased carbamylation of lens protein has been associated with severe diarrhoea..$^{22}$ Our studies provide experimental evidence for the role of ambient temperature on the lens and on the possible acceleration of the cataract forming process(es) by high temperature.

In summary, our results give evidence that both body and ambient temperature increase the temperature of the lens and that exposure to sunlight results in an additional temperature increase.

The authors thank the Department of Opthalmology at the Postgraduate Institute of Medical Education and Research in Chandigarh, India, for their help and Professor M Pandolfi, King Faisal University, Dammam, Saudi Arabia, for his comments.

\section{References}

1 Duke-Elder S. The pathological action of light upon the eye; part II, Action upon the lens theory of the genesis of the cataract. Lancet 1926; i: 1188-91, 1250-4.

2 Goldmann H. Genesis of heat cataract Arch Ophthalmol 1933; 9: 324.

3 Zigman S, Schultz JB, Yulo T, Grover D. Effects of near ultraviolet irradiation on lens and aqueous humor proteins. Isr $J$ Med Sci 1972; 8: 1590-5.

4 Pirie A. Cataract: chemical and experimental pathology; Isr J Med Sci 1972; 8: 1567-76.
5 Zigler JS, Jernigan HM, Perlanutter NS, Kinoshita JH. Photodynamic cross linking of polypeptides in intact lens. Exp Eye Res 1982; 35: 239-44.

6 Zigman S. The role of sunlight in human cataract formation. Surv Ophthalmol 1983; 27: 317-26

7 Hiller R, Giacometti L, Yuen K. Sunlight and cataract: an epidemiological investigation. Am J Epidemiol 1977; 105: 450-9.

8 Dhir SP, Detels R, Alexander ER. The role of environmental factors in cataract, pterygium and trachoma. Am J Ophthalmol $1967 ; 64: 128-35$.

9 Crabbe MJC. Low incidence of cataract in Hawaii despite high exposure to sunlight. Lancet 1983; i: 649.

10 Minassian DD, Mehra V, Jones BR. Dehydrational crisis from severe diarrhoea or heat stroke and risk of cataract. Lancet 1984; i: $751-3$.

11 Voaden MJ. Effect of temperature on cell division in the cultured rabbit lens. Exp Eye Res 1971; 11: 7-14.

12 Edwards MJ, Mulley R, Ring S, Wanner RA. Mitotic cell death and delay of mitotic activities in guinea pig embryos following brief maternal hyperthermia.J Embryol Exp Morphol 1974; 32: 593-602.

13 Schwartz B. The effect of lid closure upon the ocular temperature gradient. Invest Ophthalmol Vis Sci 1964; 3: 100-8.

14 Schwartz B. Environmental temperature and ocular temperature gradient. Arch Ophthalmol 1965; 74: 237-43.

15 Langley R, Mortimer C, McCulloch C. Experimental production of cataract by exposure to heat and light. Arch Ophthalmol 1960; 63: 473-88.

16 Lakhanpol V, Shocket SS, Richards RD, Niranki FS. Photocoagulation induced lens opacity. Arch Ophthalmol 1982; 100: 1068-70.

17 Instruction manuals for YSI tele-thermometer and series 500 and 400 temperature probes. Yellow Springs Instrument Co., Inc., Scientific Division, Yellow Springs, Ohio 45387.

18 Fatt I, Forester JF. Errors in eye tissue temperature measurement when using a metallic probe. Exp Eye Res 1972; 14: 270-6.

$19 \mathrm{Lu}-\mathrm{Ku}-\mathrm{Li}$. Effects of temperature, concentration and carboxymethylation on interactions of calf lens crystallin. Exp Eye Res 1979; 28: 717-31.

20 Miranda MN. The geographic factor in the onset of presbyopia, Trans Am Ophthalmol Soc 1979; 77: 603-21.

21 Chatterjee A. Cataract in Punjab. Symposium of human lens in relation to cataract. Ciba foundation symposium. Amsterdam: Elsevier, 1973; 19: 265-79.

22 Harding JJ, Rixon RC. Carbamylation of lens protein: a possible factor in cataractogenesis in some tropical areas. Exp Eye Res $1980 ; 31$ : 567-71.

Accepted for publication 29 October 1985. 